\title{
THERMAL properties and morphology of Polypropylene/Polycarbonate/Polypropylene-Graft-Maleic anhydride blends
}

\author{
M. S. Mat-Shayuti ${ }^{1}$, M. Z. Abdullah ${ }^{2}$ and P. S. M. Megat-Yusoff ${ }^{2}$ \\ ${ }^{1}$ Universiti Teknologi MARA, MALAYSIA \\ ${ }^{2}$ Universiti Teknologi PETRONAS, MALAYSIA
}

\begin{abstract}
This work investigates the effect of blending polycarbonate (PC) into polypropylene (PP) matrix polymer on thermal properties and morphology. The blends, containing $5 \%$ to $35 \%$ of polycarbonate and $5 \%$ compatibilizer, were compounded using twin-screw extruder and fabricated into standard tests samples using injection or compression molding. The compatibilizer used was polypropylene-graft-maleic anhydride (PP-g-MA). Thermogravimetric analysis (TGA) showed improved thermal degradation temperature of PP/PC/PP-g-MA blends compared to pure PP. As PC content increased, the thermal degradation temperature also improved. The highest improvement of thermal degradation temperature was $23.3 \%$, demonstrated by $60 / 35 / 5$ composition. It was found that the thermal stability of PP/PC blends was improved with the addition of PP-g-MA. PP-g-MA was suspected to enhance the phase adhesion between PP and PC, thus improving thermal stability. Microscopy analysis showed PC reinforcement phase existed as particulates dispersed in PP matrix phase. PC also was in irregular shapes of fibers or flakes in certain compositions, depending on PC fraction and compatibilizer content.
\end{abstract}

\section{Introduction}

Polymer blending is considered as the most versatile and economic way to engineer a material with specific desired properties. Polymer blend has been expanding widely since the first polymer blending was done between natural rubber with gutta-percha, and currently $36 \mathrm{wt} \%$ of total polymer consumption comes from polymer blends, and $80 \%$ of plastics are in the form of polymer blends, alloys, and composites [1]. Wide application of polymer blends can be found in areas such as textile, transportation, electronic, and packaging [2, 3].

Polypropylene (PP) is a commodity polymer that has relatively good mechanical properties and low-cost [4]. However, PP is also well-known for having low thermal stability or low heat distortion temperature. This shortcoming of PP makes its applications limited. Food container made from PP could not be used in oven or microwave at a relatively high temperature, electronic parts or semiconductors made from PP has small range of operating temperature, and PP coating in subsea pipelines could not withstand a relatively high crude oil temperature in a long intended lifetime. Thermal properties of $\mathrm{PP} /$ polycarbonate $(\mathrm{PC})$ blends had been the subject of few studies and improvement in PP thermal stability was reported $[5,6]$. However, little information is available regarding the relation of $\mathrm{PC}$ content with thermal properties of $\mathrm{PP} / \mathrm{PC}$ blends. Furthermore, addition of compatibilizer or third component into ternary $\mathrm{PP} / \mathrm{PC}$ blends will influence the thermal properties. Therefore, this area of $\mathrm{PP} / \mathrm{PC}$ blend requires more studies for a clearer and thorough comprehension.

From earlier researches, one of the prime objectives of blending PP with other polymer was to improve PP's disadvantage which is poor impact strength [7, 8]. Blending with PC was attempted to get PP-based material that has considerably good impact strength with sufficient stiffness. Now research on PP/PC blends has moved beyond the impact strength and stiffness, as thermal properties of the blends are also being studied.

PP and PC are immiscible with each other because of differences in polarity and solubility parameters [9], therefore they will exist as separated phases in their blend. The blend will typically possess two glass transition temperatures $(\mathrm{Tg})$, each for $\mathrm{PP}$ and $\mathrm{PC}$, and one melting temperature (Tm) of PP. Thermal behavior of PP/PC blends was investigated using differential scanning calorimeter (DSC) [10], and the result showed Tm of PP in the blends were almost similar compared to pure PP. Regardless of the changing ratio of the $\mathrm{PP} / \mathrm{PC}$ blends, the $\mathrm{Tm}$ peaks were almost similar to one another [11]. Tg values were found did not change in PP/PC blend [11].

For the case of immiscible polymer blend, normally compatibilizer is added to increase interfacial adhesion and to reduce interfacial tension between phases in the composite. The addition of compatibilizer does not only 
influence mechanical properties, but also thermal properties of PP/PC blends. Ning and Ko [12] reported that increasing amount of polypropylene-graft-maleic anhydride (PP-g-MA) from $5 \mathrm{wt} \%$ - $20 \mathrm{wt} \%$ would lead to higher Tm and lower crytallinity of the blends. In the meanwhile, blends of PP/PC/PP-grafted glycidyl methacrylate (PP-g-GMA) showed that Tm for PP stayed unchanged [13], while the $\mathrm{Tg}$ of PC shifted to lower temperature [14]. The addition of PP-g-GMA also resulted in crystallization temperature, Tc, of $\mathrm{PP}$ became $50 \mathrm{C}-8 \mathrm{oC}$ higher than that in the binary blends of PP/PC. This result might be caused by the PP-g-GMA which acted as a nucleating agent in the PP crystallization process. Dai and Ye [11] found that the Tg peaks of PP shifted to higher temperatures with addition of PPgrafted2-terbutyl-6-(3-tertbutyl-2-hydroxy-5-

methylbenzyl)-4-methylphenyl acrylic ester (PP-g-BPA) or styrene-ethylene-butylene-styrene (SEBS), whereas the Tg peaks of PC shifted to lower temperatures.

Renaut and co-workers [6] tested 75\% PP, 25\% PC, and optional $3 \%$ PP-g-MA or Terpolymer ethylene/acrylic ester/maleic anhydride (EBuAMA) blends, and through thermal gravimetry analysis (TGA), it was found that the compatibilized blends showed higher temperature for maximum degradation compared to the noncompatibilized blends. This suggested that thermal stability of PP/PC blends was improved with the addition of compatibilizer. The improvement was attributed to the changes in the morphology of the blends, where adhesion between PP and PC phases might be improved from compatibilizing. Similar reasoning has been reported for other polymer blends [15].

In several occasions, ternary blends of $\mathrm{PP} / \mathrm{PC}$ with other filler substance have been reported. Chand and Hashmi [5] studied the effect of adding PC into red mud (RM)-filled PP. The thermal stability of PP/PC/RM blends demonstrated improvement over PP/RM, and the higher PC content in the blend, the higher thermal stability achieved. In another research, PP, PC, and attapulgite (AT) were blended together to form $\mathrm{PC} / \mathrm{PP} / \mathrm{AT}$ ternary nanocomposites [16]. The produced blends had higher crystallization temperature of PP, because AT had a strong heterophase nucleation effect on $\mathrm{PP}$. On the other hand, fire testing on intumescent fire retardant of $\mathrm{PP} / \mathrm{PC} / \mathrm{ammonium}$ polyphosphate (APP)/PPg-MA demonstrated lower heat release rate compared to $\mathrm{PP} / \mathrm{APP}$, which is desirable in fire retardant behavior as thermal degradation rate of the materials will be lower [6].

Upon the promising outcomes in the thermal area of $\mathrm{PP} / \mathrm{PC}$ blends, more research is needed in order to comprehend the matter. Subsequently, this work is aimed to characterize the thermal properties and morphology of PP/PC/PP-g-MA polymer blends of various compositions. PP-g-MA as compatibilizer has been suspected to improve interfacial adhesion between PP and PC phases [6], and is intended in this work to further enhance the thermal stability.

\section{Methodology}

\subsection{Materials}

PP used was Propelinas G425, produced by Polypropylene Malaysia, and has melt volume-flow rate (MVR) of $11.0 \mathrm{~cm}^{3} / 10 \mathrm{~min}$, while PC was from the trade name Panlite ${ }^{\circledR}$ grade L-1225Y, manufactured by Teijin Kasei America Inc. (Teijin Chemicals), with MVR value of $11.0 \mathrm{~cm}^{3} / 10 \mathrm{~min}\left(300^{\circ} \mathrm{C} / 1.2 \mathrm{~kg}\right)$. The compatibilizer selected was PP-g-MA from the brand Sigma-Aldrich, with molecular weight of 9100 by gel permeation chromatography (GPC) and maleic anhydride content of $8-10 \%$.

\subsection{Sample fabrication}

PC was dried at $95^{\circ} \mathrm{C}$ for 12 hours prior to compounding to minimize hydrolytic degradation. Pellets of PP, PC and PP-g-MA were mixed according to designated weight fractions. The blends, containing between $0 \%$ to $35 \%$ of $\mathrm{PC}$ and 5\% compatibilizer were compounded by twinscrew extruder at $250^{\circ} \mathrm{C}$ and $100 \mathrm{rpm}$ before formed into standard shapes by compression molding, with temperature ranging from $190^{\circ} \mathrm{C}$ to $250^{\circ} \mathrm{C}$.

\subsection{Microscopy}

Scanning electron microscope (SEM) was used to study the morphology of the blends. Specimens were cryogenically fractured and plated with thin gold layer as preparation.

\subsection{Thermal characterization}

The thermal behaviour of PP, PC, PP-g-MA and their blends were obtained using DSC, Pyris 1, Perkin Elmer Co., USA. The samples were prepared to weight around $0.5 \mathrm{mg}$, heated from $50^{\circ} \mathrm{C}$ to $350^{\circ} \mathrm{C}$ at $10{ }^{\circ} \mathrm{C} /$ minute rate alongside a standard reference sample with sample chamber was continuously purged with dry nitrogen. Then the samples were held at $350^{\circ} \mathrm{C}$ for 5 minutes to remove any thermal history before cooled to $50^{\circ} \mathrm{C}$ at 10 ${ }^{\circ} \mathrm{C} /$ minute. Graph of heat flow versus temperature then plotted.

For TGA, specimens of about $5 \mathrm{mg}$ were heated from $25^{\circ} \mathrm{C}$ to $800^{\circ} \mathrm{C}$ at a heating rate of $10^{\circ} \mathrm{C} /$ minute. Heating was performed electrically in pure nitrogen gas atmosphere to prevent oxidation and other reaction. Weight changes of the samples were then monitored and tabulated.

\section{Results \& discussion}

\subsection{Differential Scanning Calorimetry (DSC) analysis}

DSC test was performed to determine the glass transition temperature, $\mathrm{T}_{\mathrm{g}}$ and melting temperature, $\mathrm{T}_{\mathrm{m}}$ of the blends. The heat flow profile of the DSC test is presented in Fig. 1, and the tabulated data is shown in Table $1 . \mathrm{T}_{\mathrm{m}}$ of pure PP was $164.1^{\circ} \mathrm{C}$. For $\mathrm{PC}$, its $\mathrm{T}_{\mathrm{g}}$ was $156.1^{\circ} \mathrm{C}$ and it had no $\mathrm{T}_{\mathrm{m}}$, confirming that it was an amorphous polymer. In polymer blend theory, a blend of two 
immiscible polymers will produce two $T_{g}$. However, the $\mathrm{T}_{\mathrm{g}}$ for PP could not be determined experimentally, because the theoretical value of $\mathrm{T}_{\mathrm{g}}$ for $\mathrm{PP}$ is $-10^{\circ} \mathrm{C}$, which is out of the temperature range for DSC used. All the blends showed almost the same thermal behavior, with very small difference in $T_{g}$ and $T_{m}$ values. The $T_{g}$ of PC values were ranging from $153.8^{\circ} \mathrm{C}-156.1^{\circ} \mathrm{C}$. Finally, the $\mathrm{T}_{\mathrm{m}}$ values for all the blends were from $162.0^{\circ} \mathrm{C}-163.6^{\circ} \mathrm{C}$.

For the compatibilized blends, it can be observed from the result that the values of $\mathrm{T}_{\mathrm{g}}$ for $\mathrm{PC}$ showed reduction, where the blends demonstrated lower values than that of pure PC. The reduction of $\mathrm{T}_{\mathrm{g}}$ for $\mathrm{PC}$ is suggesting that $\mathrm{PP}$ and $\mathrm{PC}$ have become slightly miscible with each other because of enhanced interaction between $\mathrm{PP}$ and PC phase, resulted from the compatibilization effect.

Table 1. Result summary of DSC test.

\begin{tabular}{|c|c|c|}
\hline Blends & $\mathbf{T}_{\mathbf{g}}$ of PC $\left({ }^{\mathbf{0}} \mathbf{C}\right)$ & $\mathbf{T}_{\mathbf{m}}\left({ }^{\mathbf{}} \mathbf{C}\right)$ \\
\hline PP & - & 163.6 \\
\hline PC & 156.1 & - \\
\hline $90 / 5 / 5$ & 153.8 & 162.9 \\
\hline $80 / 15 / 5$ & 154.1 & 162.4 \\
\hline $70 / 25 / 5$ & 153.8 & 162.0 \\
\hline $60 / 35 / 5$ & 153.8 & 162.1 \\
\hline $70 / 30$ & 153.8 & 162.5 \\
\hline
\end{tabular}

When comparing the compatibilized and noncompatibilized blends from Table 1 , for $T_{g}$ of $P C$, noncompatibilized blend had value that was very close to compatibilized blends, and the disparity could easily be a result of experimental error. The same findings were reported by Zhihui et al. [13, 14] and Dai and Ye [11] when PP-g-GMA, PP-g-BPA or SEBS were used as compatibilizer. The $\mathrm{T}_{\mathrm{g}}$ of $\mathrm{PC}$ shifted to lower temperature with the addition of PP-g-GMA, PP-g-BPA or SEBS [11], [14].

Next, the melting temperatures of the blends showed slight reduction compared to pure PP. This finding is in agreement with previous research done by Chun et al. [10], where no significant changes can be seen for PP/PC blends. The $\mathrm{T}_{\mathrm{m}}$ of $\mathrm{PP} / \mathrm{PC}$ blends were almost similar with each other regardless of PC content [11]. The addition of PP-g-GMA also did not affect $\mathrm{T}_{\mathrm{m}}$ values for PP/PC blends, as reported by Zhihui et al. [14]. In the meanwhile, it can be observed that the heat of fusion of the blends generally decreases as PC content increases. The same findings were reported previously [13, 14]. From the DSC test, there was no improvement of either $\mathrm{T}_{\mathrm{g}}$ or $\mathrm{T}_{\mathrm{m}}$ found. This finding was expected, as previous researches reported the same results. The results imply that the expected thermal improvement would not be found in the $\mathrm{T}_{\mathrm{g}}$ or $\mathrm{T}_{\mathrm{m}}$ of $\mathrm{PP} / \mathrm{PC}$ blends, but rather in their thermal degradation temperature. The explanation on this can be found in thermal gravimetry analysis (TGA) section later.

Crystallization properties such as crystallization temperature, $T_{c}$, and crystallinity, $\Phi$, of the blends can be obtained from DSC test. The $\mathrm{T}_{\mathrm{c}}$ values were determined from DSC cooling thermograms, and the values are shown in Table 2. $\mathrm{T}_{\mathrm{c}}$ of pure $\mathrm{PP}$ was $118.6^{\circ} \mathrm{C}$, which is lower than $\mathrm{T}_{\mathrm{g}}$ of pure $\mathrm{PC}$ which was $156.1^{\circ} \mathrm{C}$. This suggests that during cooling process of $\mathrm{PP} / \mathrm{PC}$ blend, the PC component solidifies before PP begins to crystallize. This behavior will affect the final properties of the blend.

Table 2. Result summary of $\mathrm{T}_{\mathrm{c}}$.

\begin{tabular}{|c|c|}
\hline Blends & $\begin{array}{c}\text { Crystallization } \\
\left.\text { Temperature, } \mathbf{T}_{\mathbf{c}} \mathbf{}^{\mathbf{}} \mathbf{C}\right)\end{array}$ \\
\hline $\mathrm{PP}$ & 118.6 \\
\hline $90 / 5 / 5$ & 122.7 \\
\hline $80 / 15 / 5$ & 119.9 \\
\hline $70 / 25 / 5$ & 120.4 \\
\hline $60 / 35 / 5$ & 118.9 \\
\hline $70 / 30$ & 119.4 \\
\hline
\end{tabular}

All the blends exhibited slightly higher $\mathrm{T}_{\mathrm{c}}$ compared to that of pure PP. Differences of the $T_{c}$ values compared to the pure PP were in the range of $0.3^{\circ} \mathrm{C}-4.1^{\circ} \mathrm{C}$. Similar results were found by Zhihui et al. [14], where PP-gGMA was used as compatibilizer. However, the increment with PP-g-GMA was $5^{\circ} \mathrm{C}-8^{\circ} \mathrm{C}$, which is higher than that of PP-g-MA. From the result, there is no clear indication whether PP-g-MA has an effect towards $\mathrm{T}_{\mathrm{c}}$ since the values for compatibilized and noncompatibilized are close to each other. Normally, higher $\mathrm{T}_{\mathrm{c}}$ is favorable because it means lower cooling time. Higher $T_{c}$ may be attributed to PC and PP-g-MA acting as nucleating agents in the PP crystallization process, based on the shifting of crystallization peak temperature for the PP/PC/PP-g-MA blends than that of pure PP. The same reasoning was reported by Renaut et al. [6].

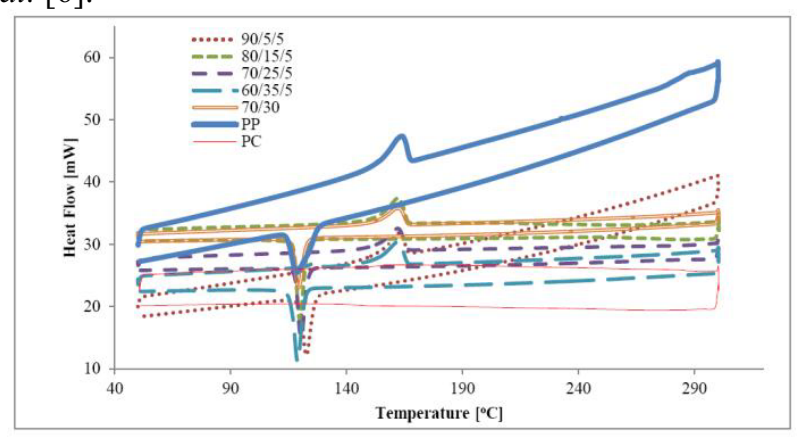

Figure 1. DSC plot of PP, PC, and PP/PC blends of various compositions. 
In the meanwhile, crystallinity, $\Phi$ were calculated using Equation 1

$$
\Phi=\frac{\Delta H_{m}}{\Delta H_{m}^{0}} \times 100 \%
$$

where $\Delta H_{m}$ is the value of enthalpy corresponding to the melting of PP and its blends, while $\Delta H_{m}^{0}$ is the extrapolated value of enthalpy corresponding to the melting of $100 \%$ crystalline PP $\left(\Delta H_{m}^{0}=209 \mathrm{~J} / \mathrm{g}\right)$. Results of enthalpy of PP melting and crystallinity are summarized in Table 3. For compatibilized blends, the highest degree of crystallization was at $80 / 15 / 5$ composition, and the lowest is at $90 / 5 / 5$ composition. The only noncompatibilized blend, 70/30 composition demonstrated the highest crystallinity and it indicates that the crystallinity of PP component in the PP/PC binary blend is higher than that of pure PP. The crystallinity of $\mathrm{PP}$ component in PP/PC blends decreases when PP-g-MA is added. It may be deduced that PP-g-MA together with $\mathrm{PC}$ will behave as crystallization suppressor in PP matrix. Renaut et al. [6] showed that PP/PC/PP-g-MA had smaller degree of crystallization than pure PP, and Ning $\&$ Ko [12] reported that increasing amount of PP-g-MA component would lead to lower crystallinity of the blends. These are in agreement with the results obtained in the Table 3. Generally in polymer science, higher crystallinity means stronger material, but at the same time more brittle. Amorphous regions on the other hand contribute towards toughness.

Table 3. Result summary of enthalpy of PP melting, and crystallinity.

\begin{tabular}{|c|c|c|}
\hline Blends & $\begin{array}{c}\text { Enthalpy of PP } \\
\text { melting, } \Delta \boldsymbol{H}_{\boldsymbol{m}} \\
\mathbf{( J / g )}\end{array}$ & $\begin{array}{c}\text { Calculated } \\
\text { crystallinity, } \mathbf{\Phi} \\
\mathbf{( \% )}\end{array}$ \\
\hline PP & 67.7 & 32.4 \\
\hline $90 / 5 / 5$ & 40.4 & 19.3 \\
\hline $80 / 15 / 5$ & 59.1 & 28.3 \\
\hline $70 / 25 / 5$ & 51.5 & 24.6 \\
\hline $60 / 35 / 5$ & 45.6 & 21.8 \\
\hline $70 / 30$ & 72.3 & 34.6 \\
\hline
\end{tabular}

\subsection{Thermogravimetry Analysis (TGA)}

Degradation temperatures of pure PP, pure PC, and $\mathrm{PP} / \mathrm{PC}$ blends with and without PP-g-MA were determined using TGA. Results of TGA are depicted in Fig. 2. Results showed that there was improvement in degradation temperature of $\mathrm{PP} / \mathrm{PC} / \mathrm{PP}-\mathrm{g}-\mathrm{MA}$ compared to pure PP. PP started to decompose at $283^{\circ} \mathrm{C}, \mathrm{PC}$ at $372^{\circ} \mathrm{C}$ and their blends at $338^{\circ} \mathrm{C}, 340^{\circ} \mathrm{C}, 344^{\circ} \mathrm{C}, 349^{\circ} \mathrm{C}, 333^{\circ} \mathrm{C}$ for $90 / 5 / 5,80 / 15 / 5,70 / 25 / 5,60 / 35 / 5$ and $70 / 30$ compositions, respectively. Pure PP, PC, and the blends degraded in one step decomposition mode. Table 4 shows the tabulated date of the TGA test.
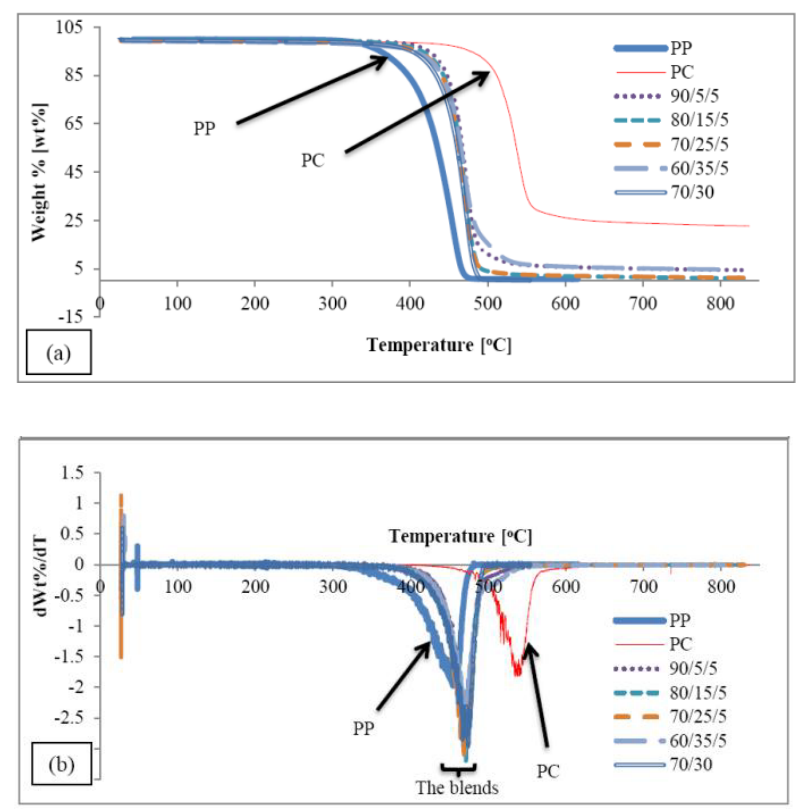

Figure 2. (a) TGA plot, (b) TGA $1^{\text {st }}$ derivative plot.

Table 4. Result summary of thermogravimetry analysis.

\begin{tabular}{|c|c|c|c|}
\hline Blends & $\begin{array}{c}\text { Initial } \\
\text { decomposi- } \\
\text { tion temp. } \\
\left.\mathbf{(}^{\mathbf{}} \mathbf{C}\right)\end{array}$ & $\begin{array}{c}\text { Maximal } \\
\text { decomposi- } \\
\text { tion temp. } \\
\left.\mathbf{(}^{\mathbf{}} \mathbf{C}\right)\end{array}$ & $\begin{array}{c}\text { Final } \\
\text { decompos } \\
\text { i-tion } \\
\text { temp. } \\
\left.\mathbf{(}^{\mathbf{0}} \mathbf{C}\right)\end{array}$ \\
\hline $\mathrm{PP}$ & 283 & 455 & 483 \\
\hline $\mathrm{PC}$ & 372 & 539 & 655 \\
\hline $90 / 5 / 5$ & 338 & 470 & 533 \\
\hline $80 / 15 / 5$ & 340 & 472 & 536 \\
\hline $70 / 25 / 5$ & 344 & 472 & 540 \\
\hline $60 / 35 / 5$ & 349 & 473 & 564 \\
\hline $70 / 30$ & 333 & 473 & 492 \\
\hline
\end{tabular}

In general, the blends are presenting intermediate thermal degradation properties between PP and PC. Compared to pure PP, PP/PC blends improvement can be found in initial degradation temperature, maximal decomposition temperature, and final decomposition temperature. The addition of PC improves the thermal stability of PP, and the relationship between thermal stability and PC content is linear. $35 \%$ of PC content in $60 / 35 / 5$ blend composition shows the highest improvement. A study conducted by Chand and Hashmi 
[5] reported the same finding where the thermal degradation resistance of $\mathrm{PP} / \mathrm{PC} / \mathrm{red}$ mud blends improved as PC content increased in PP matrix and fixed $5 \%$ red mud.

Thermal stability of PP/PC blends is improved with the addition of PP-g-MA. There is a significant enhancement of thermal stability of the compatibilized blend $(70 / 35 / 5)$ compared to the uncompatibilized blends (70/30). It may be due to the adhesion between PP and PC phases improved from the compatibilization hence increasing the blends thermal stability, as reported by Renaut et al. [6] and Lamas et al. [15].

These degradation temperatures values are important for processing purpose. The processing temperature must be high enough for polymers to melt and flow, but it must not exceed the degradation temperature to avoid deterioration of their properties. Finally, it may be deduced that thermal stability of polymer composites depends on two major factors. The first factor is the composition of the constituent polymers, and the second factor is the morphology and bonding between phases in the polymer composites.

\subsection{Morphology}

The SEM micrographs of the blends after compounding process are shown in Fig. 3, and Table 5 shows the PC particulates diameters for each blend. 90/5/5 composition showed PC particulates dispersed in PP matrix. At $80 / 15 / 5$ and $70 / 25 / 5$ compositions, the shape of dispersed PC was a mix of spheres and fibrous. 60/35/5 composition on the other hand showed some PC existed as fibers while the rest had no definite shape, and the size of it was relatively large. Finally, 70/30 composition portrayed PC reinforcement existed as particulates and flakes dispersed in PP matrix.

Table 5. Results of PC particulates diameter from SEM.

\begin{tabular}{|c|c|c|c|c|c|}
\hline Blends & $\begin{array}{c}\mathbf{9 0 / 5} / \\
\mathbf{5}\end{array}$ & $\begin{array}{c}\mathbf{8 0 / 1 5} / \\
\mathbf{5}\end{array}$ & $\begin{array}{c}\mathbf{7 0 / 2 5} / \\
\mathbf{5}\end{array}$ & $\begin{array}{c}\mathbf{6 0} / \mathbf{3 5} \\
\mathbf{5}\end{array}$ & $\mathbf{7 0 / 3 0}$ \\
\hline $\begin{array}{c}\text { PC } \\
\text { particulates } \\
\text { diameter } \\
(\mu \mathrm{m})\end{array}$ & $\begin{array}{c}3.1- \\
4.9\end{array}$ & $\begin{array}{c}1.9- \\
4.4\end{array}$ & $\begin{array}{c}3.6- \\
6.7\end{array}$ & - & $4.5-$ \\
& & & & & 11.6 \\
\hline
\end{tabular}
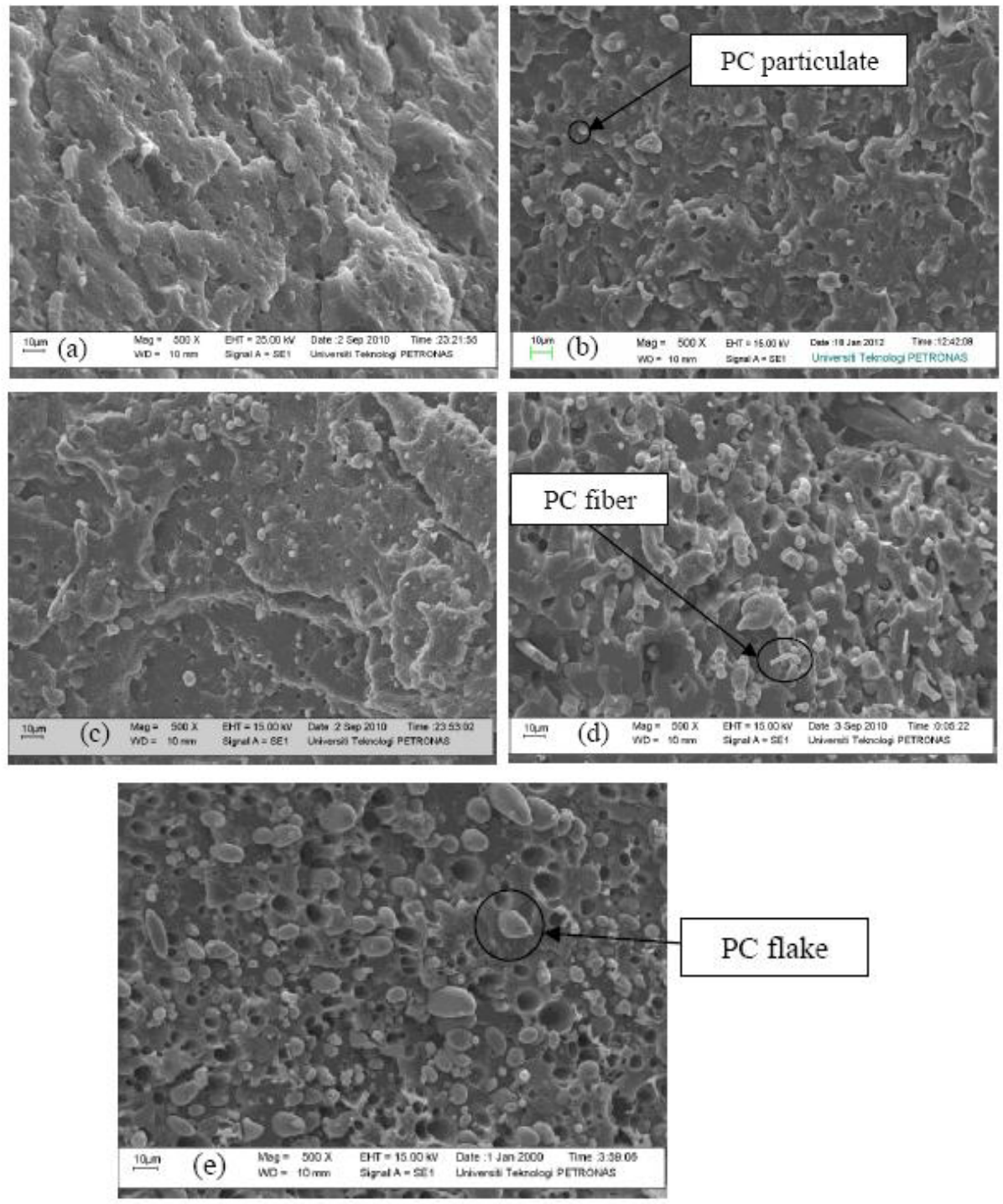

Figure 3. Scanning electron micrograph at 500X magnification of: (a) PP/PC/PP-g-MA (90/5/5), (b) PP/PC/PP-g-MA (80/15/5), (c) PP/PC/PP-g-MA (70/25/5), (d) PP/PC/PP-g-MA (60/35/5), and (e) PP/PC (70/30) 
For compatibilized blends of 90/5/5, 80/15/5, and $70 / 25 / 5$ compositions, the $\mathrm{PC}$ particulates diameters were $3.1 \mu \mathrm{m}-4.9 \mu \mathrm{m}, 1.9 \mu \mathrm{m}-4.4 \mu \mathrm{m}$, and $3.6 \mu \mathrm{m}-6.7 \mu \mathrm{m}$, respectively. For noncompatibilized blend of 70/30 composition, the morphology showed PC particulates diameters between $4.5 \mu \mathrm{m}-11.6 \mu \mathrm{m}$ dispersed uniformly in PP matrix.

Generally, it can be concluded that compatibilized blends have smaller diameter of PC particulates compared to the noncompatibilized one [17]. This is due to the compatibilizing effect of PP-g-MA which reduces interfacial tension at PP and PC phase boundary. The reduction in interfacial tension makes them less repulsive towards each other, providing better dispersion and thus smaller PC particulates size [18, 19].

In term of the pattern observed, increasing PC content will lead to an increase in PC particulates diameter. It is suspected that $5 \%$ compatibilizer was not sufficient in certain compositions. Zhihui et al. [13] reported that for PP/PC blends of 70/30 composition, the ideal compatibilizer amount can reach as high as $20 \%$. Therefore for $60 / 35 / 5$ system where interfacial area between PP and PC is larger, it is natural to assume that compatibilizer requirement should be higher than that of 70/30 system.

Finally, it can be observed that the color tone of PC reinforcement in compatibilized blends compared to the noncompatibilized blend was different. PC particulates in compatibilized blends appeared to be in a brighter color, while it was darker in noncompatibilized blend. The possible explanation is PP-g-MA coated the outer surface of PC particulate in compatibilized blends. The coating is what giving the slight increase in PP and PC phase adhesion, leading to higher thermal stability.

\section{Conclusion}

It was found that the addition of PC was successful in improving the thermal stability of PP, shown by the increments in initial degradation temperature, maximal decomposition temperature, and final decomposition temperature. The relationship of thermal stability and PC content is linear. Besides PC content, thermal stability also depends on morphology, and interfacial bonding of the blends. The highest improvement of thermal degradation temperature was $23.3 \%$, demonstrated by 60/35/5 composition.

From the SEM micrographs, it was found that PC reinforcement phase existed as particulates dispersed in PP matrix phase. At $80 / 15 / 5$ and $70 / 25 / 5$ compositions, the shape of dispersed PC was a mix of spheres and fibrous. 60/35/5 composition showed some PC existed as fibers while the rest had no definite shape. Finally, 70/30 composition portrayed PC reinforcement existed as particulates and flakes. In general, compatibilized blends have smaller diameter of PC particulates compared to the noncompatibilized one, probably due to the compatibilizing effect of PP-g-MA which reduces interfacial tension at PP and PC phase boundary.

\section{Acknowledgements}

This research was under the funding of Research Acculturation Grant Scheme (RAGS/1/2014/TK04/UITM//8) by Ministry of Education Malaysia through Faculty of Chemical Engineering of Universiti Teknologi MARA (UiTM) Selangor, and Mechanical Engineering Faculty of Universiti Teknologi PETRONAS, Malaysia.

\section{References}

1. L.A. Utracki, Polym. Blends Handbook, Springer Netherlands, pp. 3 - 170 (2014)

2. Y. Xu, Z.D. Sun, X.L. Chen, M. Chen, S.C. Hu, J. Macromolecular Science Part B-Physics 52 pp. 716725 (2013)

3. E. D. Weil, S. V. Levchik, Flame Retardants for Plastics and Textiles: Practical Applications 2nd Edition, Hanser Gardner Pubns, (2016)

4. W. Kaminsky, Polyolefins: 50 years after Ziegler and Natta I: Polyethylene and Polypropylene (Advances in Polym. Sci.) Springer, (2013)

5. N. Chand, S. A. R. Hashmi, Bulletin of Material Sci. 22(4) pp. 801 - 804 (1999)

6. N. Renaut, S. Duquesne, S. Zanardi, P. Bardollet, C. Steil, R. Delobel, J. Macromolecular Sci., Part A: Pure and Appl. Chem. 42 pp. 977 - 991 (2005)

7. B. D. Favis, J. P. Chalifoux, Polym. Eng. \& Sci. 27(21) pp. 1591 - 1600 (1987)

8. K. R. Srinivasan, A. K. Gupta, J. Appl. Polym. Sci. 53(1) pp. 1 - 17 (1994)

9. N. Nemirovski, A. Siegmann, M. Narkis, J. Macromolecular Sci., Part B 34(4) pp. 459 - 475 (1995)

10. Y. S. Chun, H. C. Jung, M. S. Han, W. N. Kim, Polym. Eng. \& Sci. 39 pp. 2304-2312 (1999)

11. S. Dai and L. Ye, Polym. for Adv. Tech. 19 pp. 1069 -1076 (2008)

12. P. Ning, T. M. Ko, Polym. Eng. \& Sci. 37(7) pp. 1226 - 1237 (1997)

13. Y. Zhihui, Z. Xiaomin, Z. Yajie, Y. Jinghua, J. Appl. Polym. Sci. 63 pp. 1857 - 1863 (1997)

14. Y. Zhihui, Z. Yajie, Z. Xiaomin, Y. Jinghua, Polym. 39(3) pp. 547 - 551 (1998)

15. L. Lamas, G. A. Mendez, A.J. Muller, M. Pracella, Eur. Polym. J. 34 pp. 1865-1870 (1998)

16. X. Gao, L. Mao, R. Jin, L. Zhang, M. Tian, Macromolecular Materials and Eng. 290 (9) pp. 899 - 905 (2005)

17. M.S. Mat-Shayuti, M. Z. Abdullah, P. S. M. MegatYusoff, Int. Conf. on Env. and Ind. Innov. 12 (2011)

18. S. Thomas, Y. Grohens, P. Jyotishkumar, Characterization of Polym. Blends: Miscibility, Morphology and Interfaces 1st Edition, Wiley-VCH, (2015)

19. M.S. Mat-Shayuti, M.Z. Abdullah, P.S.M. MegatYusoff, Asian J. of Scientific Research 6 (2), pp. 167 (2013) 